\title{
DESENVOLVIMENTO INICIAL DE PLÂNTULAS DE JUÇARA IRRIGADAS COM ÁGUA SALINA
}

\author{
DESARROLLO INICIAL DE PLÁNTULAS JUSSARA REGADAS CON AGUA \\ SALINA
}

\section{INITIAL DEVELOPMENT OF JUSSARA SEEDLINGS IRRIGATED WITH SALINE WATER}

\author{
Rosana Maria dos Santos Nani de Miranda ${ }^{1}$; Rozane Franci Moraes Tavares ${ }^{2}$; Tâmara \\ Moreira Silva ${ }^{3}$; Danilo Força Baroni ${ }^{4}$; Almy Junior Cordeiro de Carvalho ${ }^{5}$
}

DOI: https://doi.org/10.31692/978-65-991061-4-9.47-60

\begin{abstract}
RESUMO
O palmiteiro juçara é uma espécie de grande importância socioeconômica devido ao seu sabor, riqueza nutricional, e presença na alimentação humana e animal. Entretanto, a maior parte de sua exploração acontece de forma intensa, ilegal e predatória, resultando em uma erosão genética substancial, causando ameaça a regeneração da espécie. Além disso, o plantio de palmeiras pode ocorrer em solos salinos, irrigados ou não com água salina, tornando um fator limitante para crescimento e produtividade da cultura. Sendo assim, o objetivo nessa pesquisa foi avaliar o efeito da salinidade do substrato na emergência e desenvolvimento inicial de plântulas de juçara. $O$ delineamento foi em

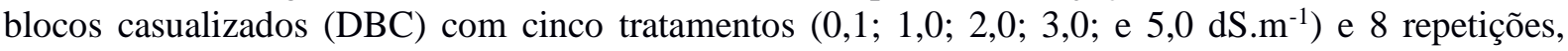
contendo 25 sementes para cada repetição, semeadas em tubetes de $290 \mathrm{~cm}^{3}$. O experimento foi conduzido por um período de 60 dias após a semeadura, aplicando diariamente $75 \mathrm{ml}$ de água por tubete, com a concentração salina determinada em cada tratamento. Foram realizadas as seguintes avaliações: emergência (E), tempo médio de emergência (TME), índice de velocidade de emergência (IVE), comprimento da parte aérea (CPA), diâmetro do coleto (DC), massa seca da parte aérea (MSPA), e massa seca do sistema radicular (MSSR). Desta forma, verificou-se que o aumento das soluções salinas acima de $1 \mathrm{dS} . \mathrm{m}^{-1}$ reduz a emergência das sementes, assim como o crescimento da parte aérea (comprimento, diâmetro, e massas secas), porém, condutividades até $5 \mathrm{dS} \cdot \mathrm{m}^{-1}$ não interferem no TME e no IVE. Portanto, a água de irrigação contendo até $5 \mathrm{dS} . \mathrm{m}^{-1}$ pode causar danos nas sementes de juçara, retardando sua emergência e prejudicando os aspectos morfológicos na produção de mudas.
\end{abstract}

Palavras-Chave: Euterpe edulis M., estresse salino, emergência.

\section{RESUMEN}

La palma de jussara es una especie de gran importancia socioeconómica debido a su sabor, riqueza nutricional y presencia en la alimentación humana y animal. Sin embargo, la mayor parte de su explotación es intensa, ilegal y depredadora, lo que resulta en una erosión genética sustancial, que amenaza la regeneración de la especie. Además, la siembra de palma puede ocurrir en suelos salinos, regados o no con agua salina, lo que lo convierte en un factor limitante para el crecimiento y rendimiento de los cultivos. Por lo tanto, el objetivo de esta investigación fue evaluar el efecto de la salinidad del sustrato en la emergencia y el desarrollo inicial de las plántulas de jussara. El diseño experimental fue un diseño de bloques al azar con cinco tratamientos $\left(0.1,1.0,2.0,3.0\right.$ y $\left.5.0 \mathrm{dS} . \mathrm{m}^{-1}\right)$ y

\footnotetext{
${ }^{1}$ Graduanda em Engenharia Agronômica, Universidade Estadual do Norte Fluminense Darcy Ribeiro, ronani.uenf@gmail.com

${ }^{2}$ Doutoranda do Programa de Pós-graduação em Produção Vegetal, Universidade Estadual do Norte Fluminense Darcy Ribeiro, rozane.franci@gmail.com

3 Doutoranda do Programa de Pós-graduação em Agronomia, Universidade Estadual do Sudoeste da Bahia, tammoreiras@gmail.com

${ }^{4}$ Doutorando do Programa de Pós-graduação em Produção Vegetal, Universidade Estadual do Norte Fluminense Darcy Ribeiro, baronidf@gmail.com

${ }^{5}$ Professor Doutor, Universidade Estadual do Norte Fluminense Darcy Ribeiro, almy@ fruticultura.org
} 
8 repeticiones, que contenían 25 semillas para cada replicación. sembrado en tubos de $290 \mathrm{~cm}^{3}$. El experimento se realizó durante 60 días después de la siembra, aplicando diariamente $75 \mathrm{ml}$ de agua por tubo, con la concentración de solución salina determinada en cada tratamiento. Se realizaron las siguientes evaluaciones: emergencia (E), tiempo medio de emergencia (TME), índice de velocidad de emergencia (IVE), longitud del brote (CPA), diámetro del tallo (DC), masa seca del brote (MSPA), y la masa seca del sistema radicular (MSSR). Por lo tanto, se encontró que el aumento de las soluciones salinas por encima de $1 \mathrm{dS} \cdot \mathrm{m}^{-1}$ redujo la aparición de semillas, así como el crecimiento de brotes (longitud, diámetro y masa seca), pero la conductividad hasta $5 \mathrm{dS} . \mathrm{m}^{-1}$ no interfiere con TME y IVE. Por lo tanto, el agua de riego que contiene hasta $5 \mathrm{dS} \cdot \mathrm{m}^{-1}$ puede causar daños a las semillas de jussara, retrasando su aparición y perjudicando los aspectos morfológicos en la producción de plántulas.

Palabras Clave: Euterpe edulis M., estrés salino, emergencia.

\begin{abstract}
The jussara palm is a species of great socioeconomic importance due to its flavor, nutritional richness, and presence in human and animal food. However, most of its exploitation is intense, illegal and predatory, resulting in substantial genetic erosion, threatening the regeneration of the species. In addition, palm planting can occur in saline soils, irrigated or not with saline water, making it a limiting factor for crop growth and yield. Therefore, the objective of this research was to evaluate the effect of substrate salinity on the emergence and initial development of jussara seedlings. The experimental design was a randomized block design with five treatments $\left(0.1,1.0,2.0,3.0\right.$, and $\left.5.0 \mathrm{dS} . \mathrm{m}^{-1}\right)$ and 8 replications, containing 25 seeds for each replication. sown in $290 \mathrm{~cm}^{3}$ tubes. The experiment was conducted for a period of 60 days after sowing, daily applying $75 \mathrm{ml}$ of water per tube, with the saline concentration determined in each treatment. The following evaluations were performed: emergency (E), mean emergency time (TME), emergency speed index (IVE), shoot length (CPA), stem diameter (DC), shoot dry mass (MSPA), and dry mass of the root system (MSSR). Thus, it was found that the increase of saline solutions above $1 \mathrm{dS} . \mathrm{m}^{-1}$ reduced seed emergence, as well as shoot growth (length, diameter, and dry mass), but conductivity up to $5 \mathrm{dS} . \mathrm{m}^{-1}$ do not interfere with TME and IVE. Therefore, irrigation water containing up to $5 \mathrm{dS} \cdot \mathrm{m}^{-1}$ can cause damage to jussara seeds, delaying their emergence and impairing morphological aspects in seedling production.
\end{abstract}

Keywords: Euterpe edulis M., saline stress, emergency.

\title{
INTRODUÇÃO
}

O palmiteiro juçara, (Euterpe edulis M.) é uma das culturas no Brasil que mais produz palmito comestível, destacando-se pelo sabor, riqueza nutricional, abundância durante o ano, e fornecendo alimento a várias espécies animais com seus frutos e sementes. Entretanto, a sua exploração ocorre de forma intensa, ilegal e predatória, resultando em uma erosão genética substancial, proporcionando uma ameaça à regeneração da espécie, levando a inclusão da espécie na Lista Oficial das Espécies da Flora Brasileira Ameaçadas de Extinção (ROYER et al., 2016). Logo, a carência por uma forma de preservação e plantios para reflorestamento tem aguçado o interesse de vários pesquisadores (FIGLIORIA et al., 1987).

Devido à conscientização pela necessidade de programas de recomposição e proteção ambiental, tem-se aumentado a demanda por mudas florestais de espécies nativas (NASCIMENTO et al., 2012), principalmente de espécies como a juçara, que tem elevada 
importância na dinâmica da floresta, devido sua abundante produção de frutos e sua amplitude de produção, tornando-a espécie-chave para a manutenção da fauna (REIS, 1995).

Entretanto, um dos principais fatores ambientais que limitam o crescimento e produtividade das plantas é a salinidade (MUNNS, 2002; L.V. et al., 2008). Assim, os efeitos tóxicos que aparecem em ambientes com elevadas concentrações de sais provocam distúrbios funcionais e danos no processo metabólico (SILVA E.N. et al., 2009). Os potenciais hídricos muitos negativos, especialmente no início da embebição, influenciam na absorção de água, podendo inviabilizar a sequência dos eventos relacionados ao processo germinativo das sementes. O dano é mais evidenciado, na fase de plântulas, onde as atividades metabólicas de desenvolvimento das sementes estão mais sujeitas a ação da salinidade (De SOUZA, 2011).

Quando há a presença de teor salino no solo ou na água de irrigação, especialmente de cloreto de sódio $(\mathrm{NaCl})$, de início, a germinação é afetada pelo fato da ação osmótica ocasionar dificuldade na absorção de água para reidratar os tecidos, e intensificar a respiração e todas as atividades metabólicas que culminam com o fornecimento de energia e nutrientes necessários para a retomada do crescimento do eixo embrionário, ocasionando no aparecimento de plantas anormais pela razão do efeito tóxico dos sais sobre a semente (LIMA et al., 2005), consequentemente, ocorre a queda de rendimento das culturas (FLOWERS, 2004). Entretanto, palmeiras, de uma maneira geral, desenvolvem-se bem sobre condições salinas. Desta forma, tem sido apresentada a possibilidade do uso de solos salinos, irrigados ou não com água salina em diversas espécies de palmeiras, como Cocos nucifera L. (FERREIRA NETO et al., 2002; MARINHO et al., 2005); Bactris gasipaes (FERNANDES et al., 2003) e Copernicia prunifera (HOLANDA, 2011), através de concentrações mais elevadas de sais com essas espécies.

Para o processo de emergência de plântulas dois fatores ocorrem: a energia contida no endosperma ou cotilédone, e a profundidade na qual a semente é inserida no substrato para semeadura (HACKBART E CORDAZZO, 2003). Com isso, para a obtenção de uma ótima formação de mudas é altamente desejável que as sementes tenham características como uma germinação rápida e uniforme, consequentemente com uma imediata emergência. Porém, se as plântulas permanecerem nos estádios iniciais de desenvolvimento, maior é a vulnerabilidade que estas terão em condições adversas do meio, e o processo de emergência do solo torna-se mais lento caso a plântula fique mais tempo a essas condições (MARTINS et al., 1999). De acordo com Fonseca (2000) e Bonfim (2007) os parâmetros que são mais utilizados para obterem uma maior facilidade nas medições, é o aspecto morfológico das plantas, pois determinam um padrão de qualidade das mudas florestais. 
Dado o exposto, o objetivo nessa pesquisa foi avaliar o efeito da salinidade no substrato em relação a emergência e desenvolvimento inicial de plântulas de juçara.

\section{FUNDAMENTAÇÃO TEÓRICA}

A juçara é uma das principais espécies com maior representatividade na Mata Atlântica, por obter um reconhecimento econômico (ROYER, 2016) e por ser de fácil identificação no interior da floresta possibilita uma alta procura pela exploração da cultura no ecossistema (REIZ et al., 1978).

Ashraf e Harris (2004) apresentam que os mecanismos de tolerância nas plantas devido ao estresse salino podem ser importantes para os processos de controle de absorção, transporte e distribuição dos íons em toda planta. De modo geral, a quantidade salina presente nas plantas pode inibir seu crescimento de acordo com os efeitos osmóticos e tóxicos dos íons (MUNNS, 2002; L.V. et al., 2008).

Contudo, o desenvolvimento de palmeiras, de uma maneira geral, em condições salinas ocorre de forma adaptável, no entanto, poucas são as informações em literaturas sobre esse efeito de estresse nas espécies com a observação em emergência e vigor das sementes (TESTER; DAVÉNPORT, 2003).

\section{METODOLOGIA}

O experimento foi instalado em casa de vegetação no Campus da Universidade Estadual do Norte Fluminense Darcy Ribeiro - UENF, situada a 2119'23" latitude Sul e $41^{\circ} 10^{\prime} 40^{\prime \prime}$ longitude Oeste; Altitude $=14$ metros acima do mar. Decorreu-se no período do dia 14 de novembro de 2017 até o dia 15 de janeiro de 2018, durante 60 dias consecutivos.

As sementes de juçara foram coletadas no Município de Venda Nova do Imigrante (Latitude $=-20^{\circ} 33^{\prime} 49^{\prime \prime}$, Longitude $=-41.130420^{\circ} 20^{\prime} 6^{\prime \prime}$ Sul, 41 ${ }^{\circ} 7^{\prime} 49^{\prime \prime}$ Oeste; Altitude $=708$ metros acima do mar), no Estado do Espírito Santo. Após a coleta, o lote das sementes foi enviado até Unidade de Apoio à Pesquisa (UAP), da Universidade Estadual do Norte Fluminense Darcy Ribeiro, no Estado do Rio de Janeiro.

Durante a condução do experimento, as condições ambientais internas da casa de vegetação foram registradas: a temperatura do ar ( $\left.\mathrm{T}_{\mathrm{ar}}\right)$, umidade relativa (UR\%) em mínimas, médias e máximas pela microestação Datalog modelo Watch Dog weather station, spectrum tecnologies 2000 séries, programado para realizar leituras em intervalos de uma hora (Figura 1), e a radiação incidente (RI) foi obtida a média de $300 \mu \mathrm{mol} \mathrm{m} \mathrm{m}^{-2} \mathrm{~s}^{-1}$.

As sementes foram lixadas superficialmente para obter uma entrada de solução com 
maior facilidade, em seguida, foram semeadas em tubetes de volume de $290 \mathrm{~cm}^{3}$ contendo substrato basaplant ${ }^{\circledR}$ Hortaliças BX, com as seguintes características: umidade de 50\%, capacidade de retenção igual a $150 \%$, condutividade elétrica de $2,5 \mathrm{mS} . \mathrm{cm}^{-1}$, e pH igual a 5,8. As sementes foram colocadas a uma profundidade de 1 centímetro, em ambiente protegido.

Figura 1: Temperatura e umidade relativa do ar (\%), em mínimas, médias e máximas durante a condução do experimento. UENF, Campos dos Goytacazes-RJ. Fonte: Silva, 2018.

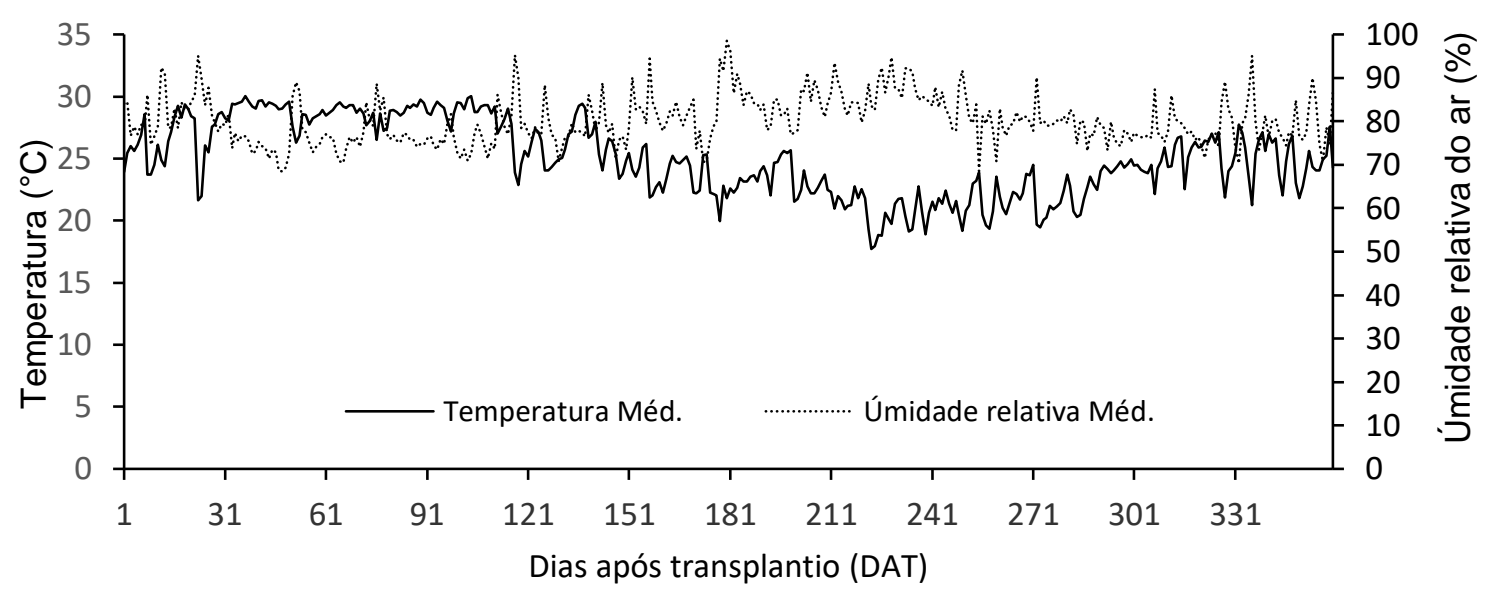

O delineamento foi em blocos casualizados (DBC) com cinco tratamentos, expresso em condutividade elétrica $\left(0,1 ; 1,0 ; 2,0 ; 3,0\right.$ e 5,0 dS.m $\left.{ }^{-1}\right)$ com oito repetições, cada repetição continha 25 tubetes com uma semente para compor a unidade experimental. As águas salinas foram preparadas por meio de adição de cloreto de sódio $(\mathrm{NaCl})$ à agua proveniente do abastecimento urbano, sendo assim, para determinar a condutividade elétrica, foi feito o cálculo para a quantidade de sal utilizada em cada tratamento, utilizando-se a equação 1, de Cavalcante et al. (2010): I) $1^{\text {a }}$ dose, tratamento controle, correspondendo a $0,1 \mathrm{dS} \cdot \mathrm{m}^{-1}$ (sendo esta a condutividade elétrica do abastecimento urbano); II) $2^{\text {a }}$ dose, solução salina contendo 0,526 g. $\mathrm{L}^{-1}$ de $\mathrm{NaCl}$ correspondendo a condutividade elétrica de $1,0 \mathrm{dS} . \mathrm{m}^{-1}$; III) $3^{\mathrm{a}}$ dose, solução salina contendo 1,111 g.L $\mathrm{L}^{-1}$ de $\mathrm{NaCl}$ referente a condutividade elétrica de 2,0 dS.m ${ }^{-1}$; IV) $4^{\mathrm{a}}$ dose, solução salina contendo 1,695 g.L.-1 de $\mathrm{NaCl}$ correspondendo a condutividade elétrica de 3,0 dS.m ${ }^{-1}$; e V) $5^{\mathrm{a}}$ dose, solução salina contendo 2,864 g.L.-1 de NaCl referente a condutividade elétrica de 5,0 dS.m ${ }^{-1}$. O grau de pureza do sal utilizado foi de $\geq 99,9 \%$ e o peso equivalente igual a 58,50 .

$$
C S=0,01\left[\frac{(C E d-C E a u)}{G P}\right] * P e q
$$

\section{Onde:}

$\mathrm{CS}=$ Concentração de cada espécie iônica $\left(\mathrm{g} . \mathrm{L}^{1}\right)$

CEd = Condutividade elétrica desejada

$\mathrm{CEau}=$ Condutividade elétrica da água oriunda do abastecimento urbano 
$\mathrm{GP}=$ Grau de pureza de cada sal

Peq $=$ Peso equivalente

Após a elaboração das soluções foi aferida a condutividade elétrica utilizando-se o condutivímetro digital de bancada para a solução aquosa, modelo MCA - 150.1. As soluções foram preparadas semanalmente e armazenadas em recipientes de polietileno hermeticamente fechados em local fresco e à sombra, de modo a evitar a evaporação e variação de temperatura da solução. A aplicação dos tratamentos foi durante a emergência das plantas, as sementes eram diariamente irrigadas, e em cada tubete aplicava-se $75 \mathrm{ml}$ de solução, desta maneira, eram irrigados $525 \mathrm{ml}$ de solução por semana.

A cada dia, foi realizada a avaliação da emergência e foram feitas contagens do número de plântulas até que a germinação ficasse ausente completamente, em um período de 60 dias. Determinou-se como critério para a avaliação da emergência a parte aérea emitida. A coleta dos dados em cada repetição do experimento foi utilizada para o cálculo do tempo médio de emergência (TME), sendo feito a contagem do número de plântulas emergidas diariamente e feito à média dos dias requeridos para emergência de cada repetição, e determinou-se também a taxa de germinação, através da média das sementes germinadas de cada repetição em porcentagem.

Para a determinação dos parâmetros morfológicos foi avaliado o comprimento da plântula com régua graduada milimetrada, com resultados expressos em centímetro, e o diâmetro do coleto, medido com paquímetro digital com 1 milímetro de precisão, resultados expressos em milímetro.

A coleta para avaliação da produção de biomassa seca das mudas foi realizada no final do experimento, separando raiz e parte aérea, sendo o sistema radicular lavado em água corrente para limpeza das raízes. No final, a soma da parte aérea e raiz forneceu a biomassa fresca total. $\mathrm{O}$ material fresco foi acondicionado em sacos de papel tipo Kraft, tarados e pesados em balança digital analítica com precisão de 0,01g. Após a pesagem da biomassa fresca, as mudas foram colocadas para secagem em estufa com circulação forçada de ar a $70{ }^{\circ} \mathrm{C}$ por 72 horas, sendo posteriormente pesada e, então, determinado os parâmetros biomassa seca da parte aérea, e a biomassa seca radicular, os resultados foram expressos em gramas.

O principal índice baseado nas relações de parâmetros morfológicos e que foi utilizado na avaliação da qualidade de mudas foi a relação da biomassa seca da parte aérea com a biomassa seca radicular (FONSECA et al., 2000).

Os dados foram submetidos à análise de variância (ANOVA) pelo teste $\mathrm{F}$ ao nível de significância de $5 \%$ de probabilidade para a comparação dos tratamentos. Utilizou-se a análise de 
regressão, com teste $\mathrm{F}$ significativo da análise de variância da regressão. O software estatístico utilizado foi o Sisvar (Versão 5.6).

\section{RESULTADOS E DISCUSSÃO}

Ao analisar os resultados da emergência das sementes de juçara (Figura 2), foi possível verificar efeito linear decrescente da regressão, em que o aumento na concentração salina da água de irrigação, causou redução de 67,0\% na emergência das sementes em 5 dS.m ${ }^{1}$ quando comparado ao controle. Sendo assim, o excesso de íons de cloreto de sódio $(\mathrm{NaCl})$ presentes no substrato, pode ter inibido a germinação causando intumescência protoplasmática, afetando a atividade enzimática e resultando na produção inadequada de energia e distúrbios na assimilação de nutrientes, principalmente o nitrogênio, isso é ocasionado devido ao baixo potencial hídrico, em função do efeito osmótico (LIMA et al.,2005). O gradiente osmótico formado pela concentração de sais limita a absorção de água pela semente (BARONI, 2018), afetando diretamente o desenvolvimento do embrião, o qual depende da pressão de turgescência das células para que os processos de divisão e expansão celulares ocorram (KLAFKE et al., 2012).

Figura 2. Emergência (\%) de sementes de juçara irrigadas com águas salinas em diferentes condutividades elétricas ao longo de 60 dias.

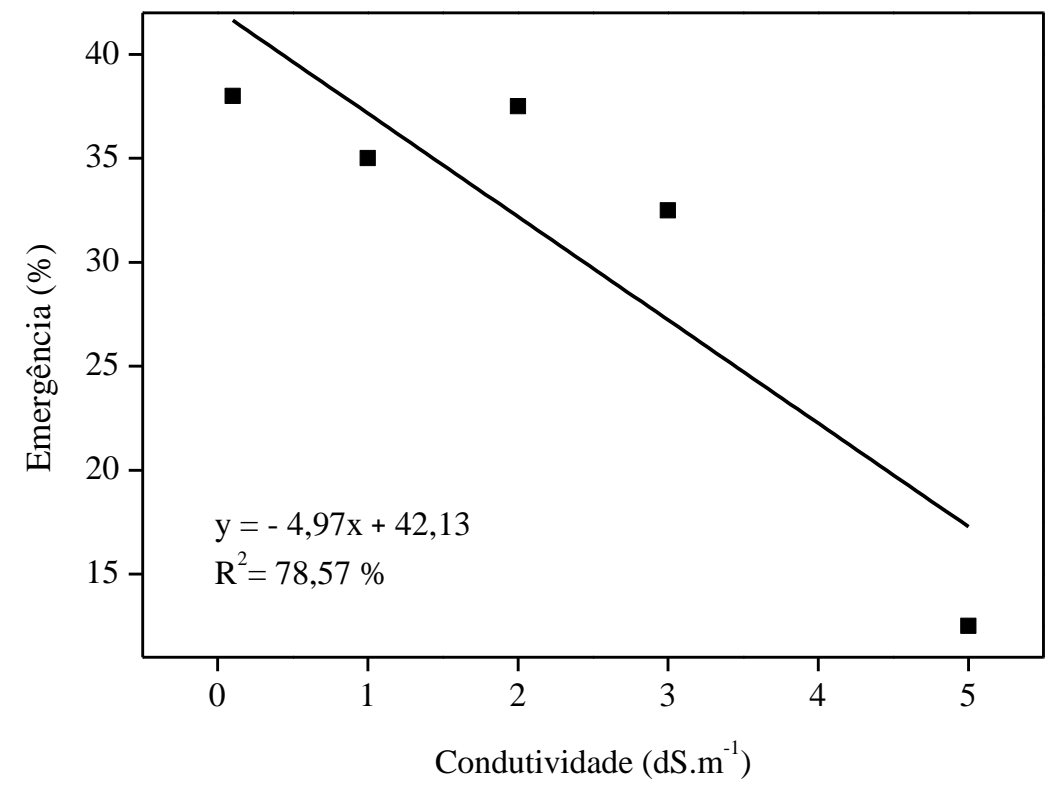

Fonte: Própria (2018)

Ao analisar o TME (Figura 3) e o IVE (Figura 4), testes recomendados para determinação do vigor de sementes, não foi encontrada diferença entre as concentrações salinas da água de irrigação. Ao correlacionar tais variáveis com a emergência (Figura 2), acredita-se que a salinização da água de irrigação em todas as doses utilizadas, tenha inibido 
apenas a germinação das sementes de menor vigor. Com isso, obteve-se uma redução significativa na emergência das sementes, enquanto que o TME e o IVE não foram afetados. Em condições inadequadas para germinação as sementes de menor vigor são menos resistentes que as vigorosas, sendo assim, possuem menor capacidade de superar tais condições (BARONI, 2018).

Figura 3. Tempo médio de emergência (TME) de sementes de juçara irrigadas com águas salinas em diferentes condutividades elétricas ao longo de 60 dias.

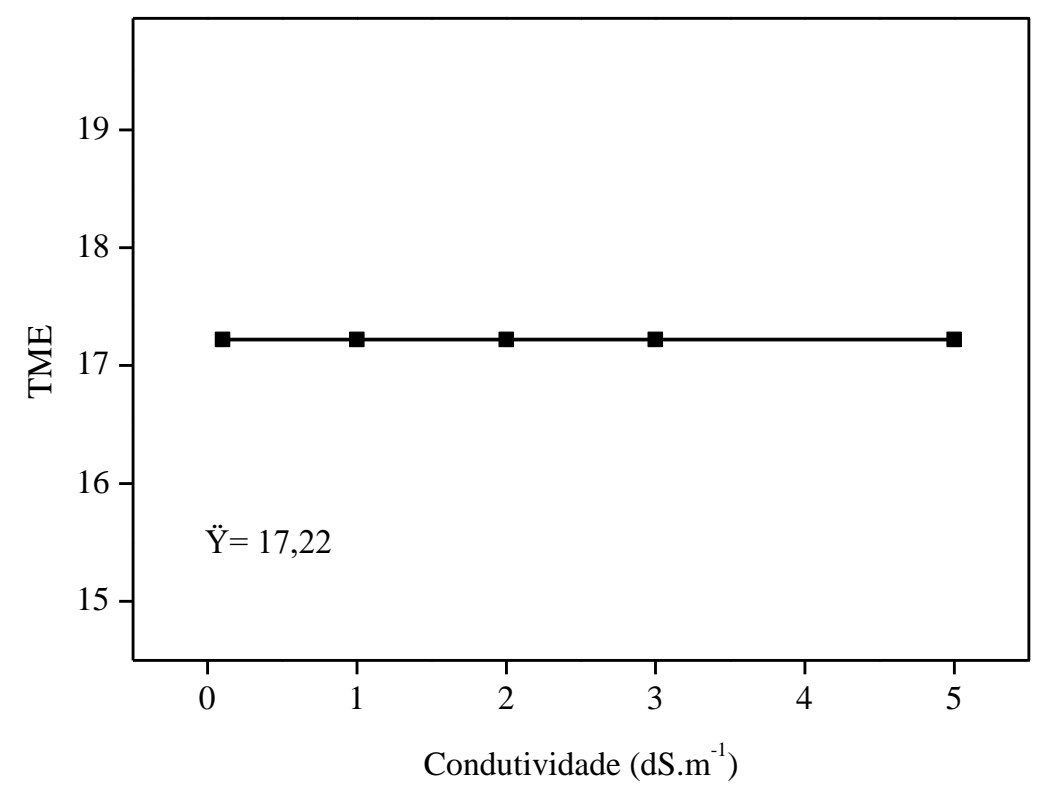

Fonte: Própria (2018)

Figura 4. Índice de velocidade de emergência (IVE) de sementes de juçara irrigadas com águas salinas em diferentes condutividades elétricas ao longo de 60 dias.

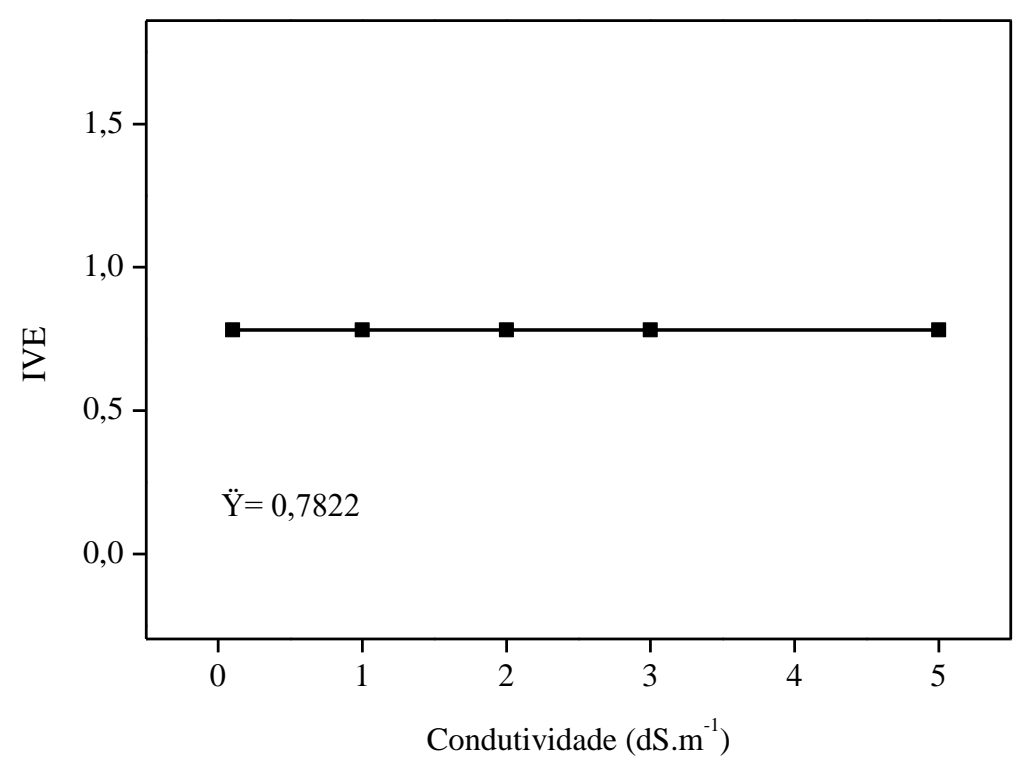

Fonte: Própria (2018) 
A salinidade da água de irrigação interferiu não somente na emergência das plântulas, mas também no desenvolvimento vegetativo das mesmas. Para a variável comprimento da parte aérea (Figura 5), houve efeito linear decrescente de regressão, em que o aumento da concentração salina até $5 \mathrm{dS} \cdot \mathrm{m}^{-1}$ causou redução de 59,3\% em comparação com o controle (água com condutividade elétrica de $0,1 \mathrm{dS} \cdot \mathrm{m}^{-1}$ ).

Figura 5. Comprimento da parte aérea (CPA) das plântulas de juçara irrigadas com águas salinas em diferentes condutividades elétricas ao longo de 60 dias.

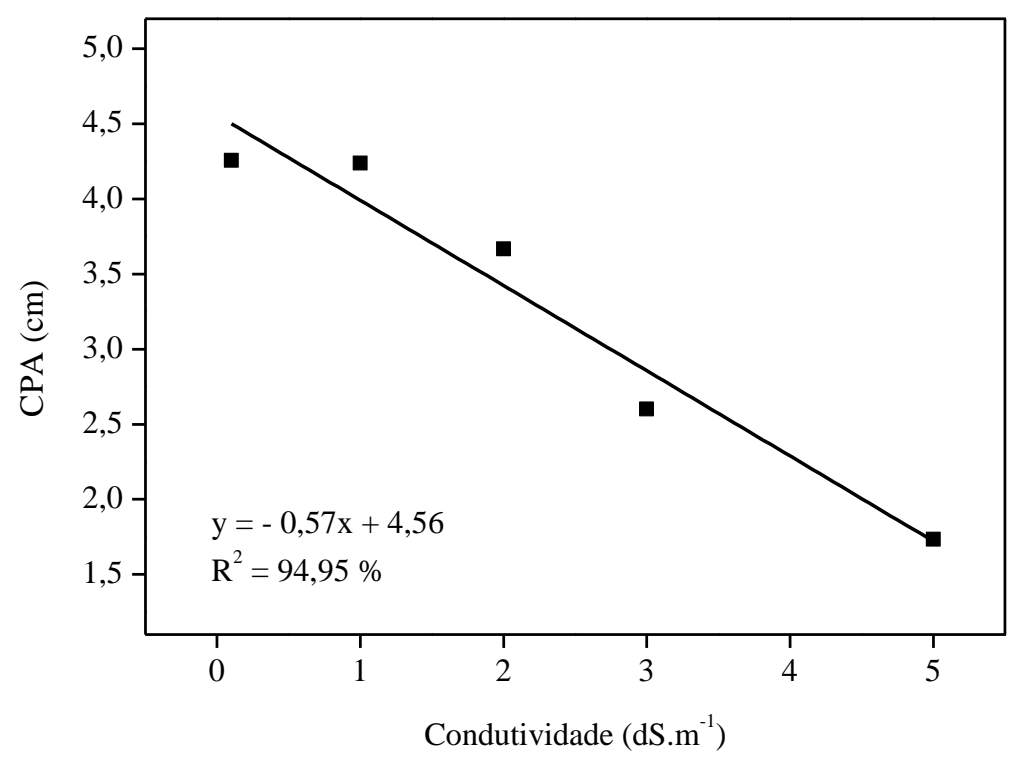

Fonte: Própria (2018)

Resultado semelhante ao CPA foi obtido para o diâmetro do coleto (DC) (Figura 6), entretanto em menor intensidade. A variável CPA sofreu uma redução de 2,64 vezes, quando as plântulas foram irrigadas com água de condutividade elétrica $5 \mathrm{dS} . \mathrm{m}^{-1}$, se comparada ao controle. O DC por sua vez, apresentou redução apenas de 1,48 vezes para as mesmas condições. A redução do comprimento das plântulas de juçara é devido às mudanças na turgescência celular, em função da redução da síntese de proteína às condições de estresse hídrico causado pela salinidade do meio, ocasionando redução na expansão celular e desta forma reduzindo o crescimento das plântulas (TAIZ E ZEIGER, 2009). 
Figura 6. Diâmetro do coleto (DC) das plântulas de Euterpe edulis M. irrigadas com águas salinas em diferentes condutividades elétricas ao longo de 60 dias.

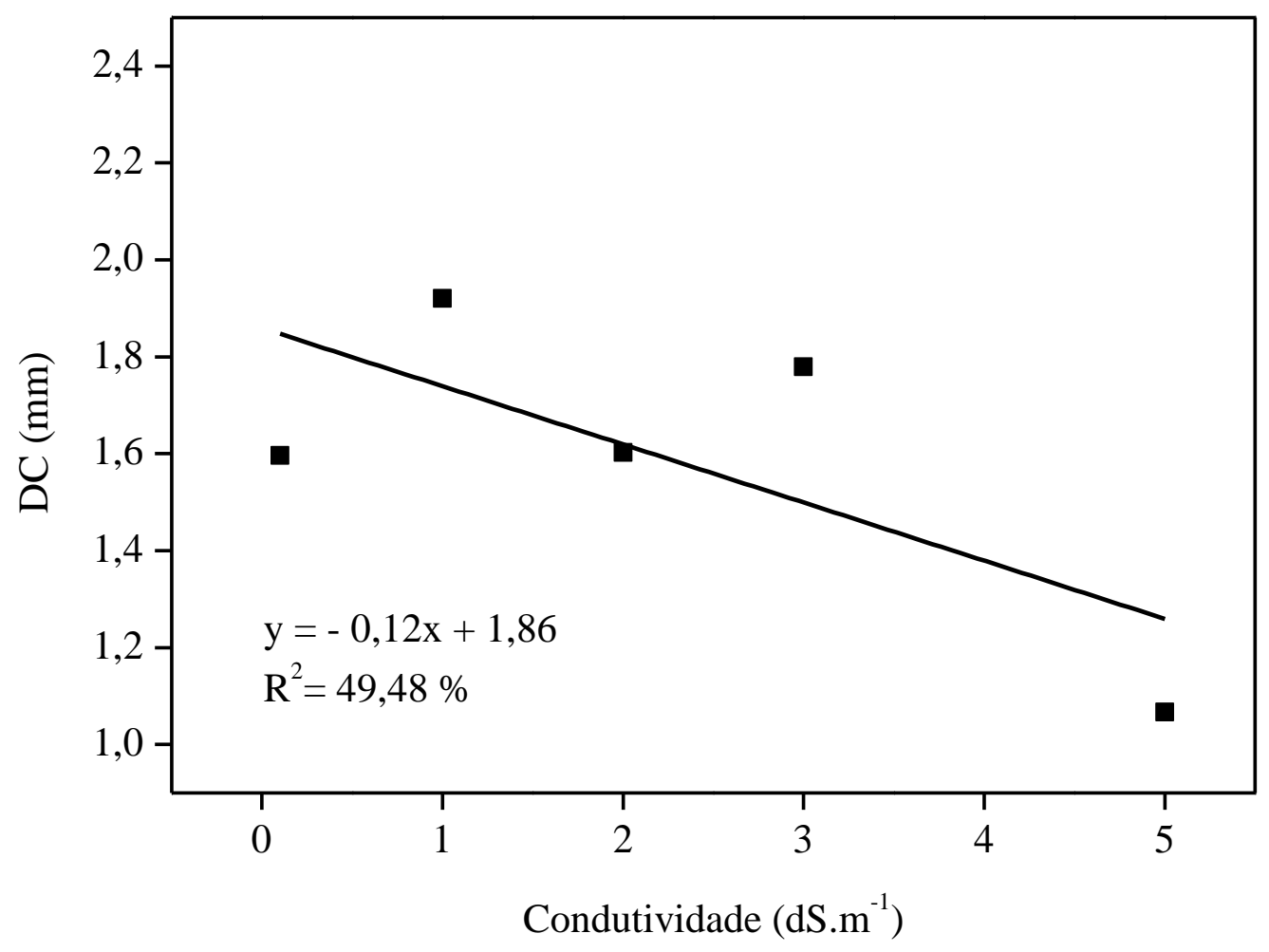

Fonte: Própria (2018)

A redução do crescimento da parte aérea observado nas Figuras 5 e 6 resultou consequentemente em uma menor deposição de massa seca pelas plantas. $\mathrm{O}$ crescimento da parte aérea e do sistema radicular está altamente relacionado, de modo que a interferência no desenvolvimento de uma parte influenciará o desenvolvimento da outra. Tal característica foi facilmente observada ao analisar as Figuras 7 e 8, ao verificar que a redução de 55,0\% do crescimento radicular em $5 \mathrm{dS} . \mathrm{m}^{-1}$ relacionado ao controle, obtido pela variável MSSR (Figura 7), causada pelo aumento da salinização do substrato via água de irrigação, reduziu também o crescimento da parte aérea, ao observar a redução das variáveis CPA, DC e MSPA (Figura 8). Essa redução tanto na biomassa seca da parte aérea quanto da raiz pode ser explicada pela redução do metabolismo das sementes, em função da menor disponibilidade de água presente para a degradação das reservas e translocação dos nutrientes metabolizados, pois a água é osmoticamente retida em solução salina, de maneira que, com o aumento dos sais na solução torna a água cada vez menos disponível para as plantas (BARTELS SUNKAR, 2005). 
Figura 7. Massa seca da parte aérea (MSPA) das plântulas de juçara irrigadas com águas salinas em diferentes condutividades elétricas ao longo de 60 dias.

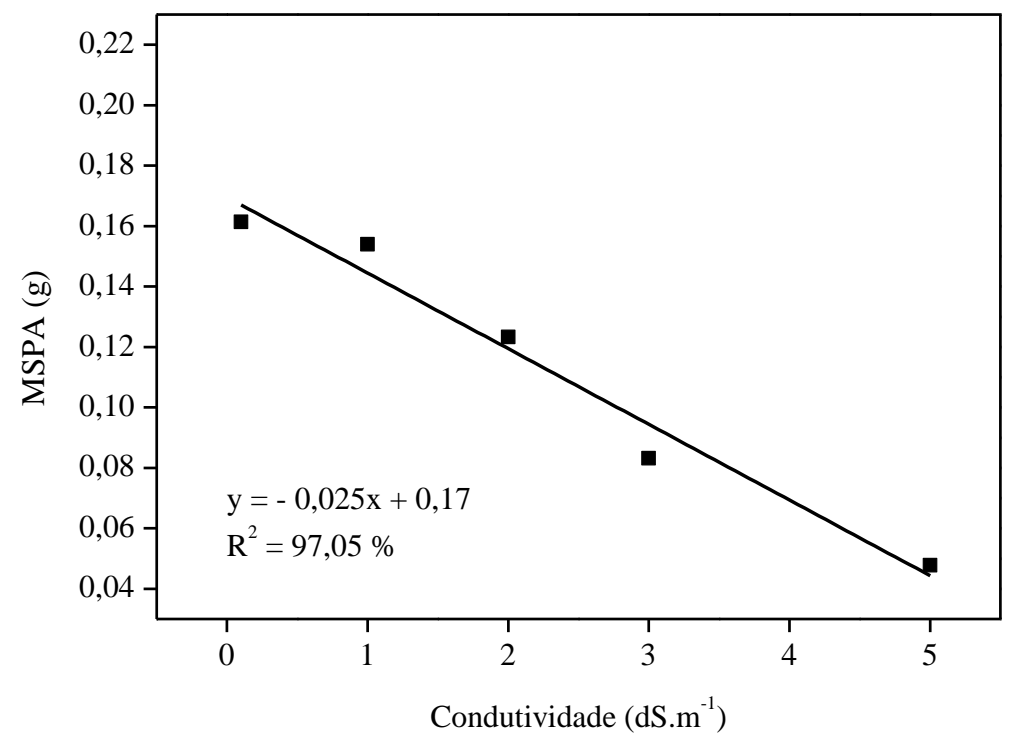

Fonte: Própria (2018)

Figura 8. Massa seca do sistema radicular (MSSR) das plântulas de juçara irrigadas com águas salinas em diferentes condutividades elétricas ao longo de 60 dias.

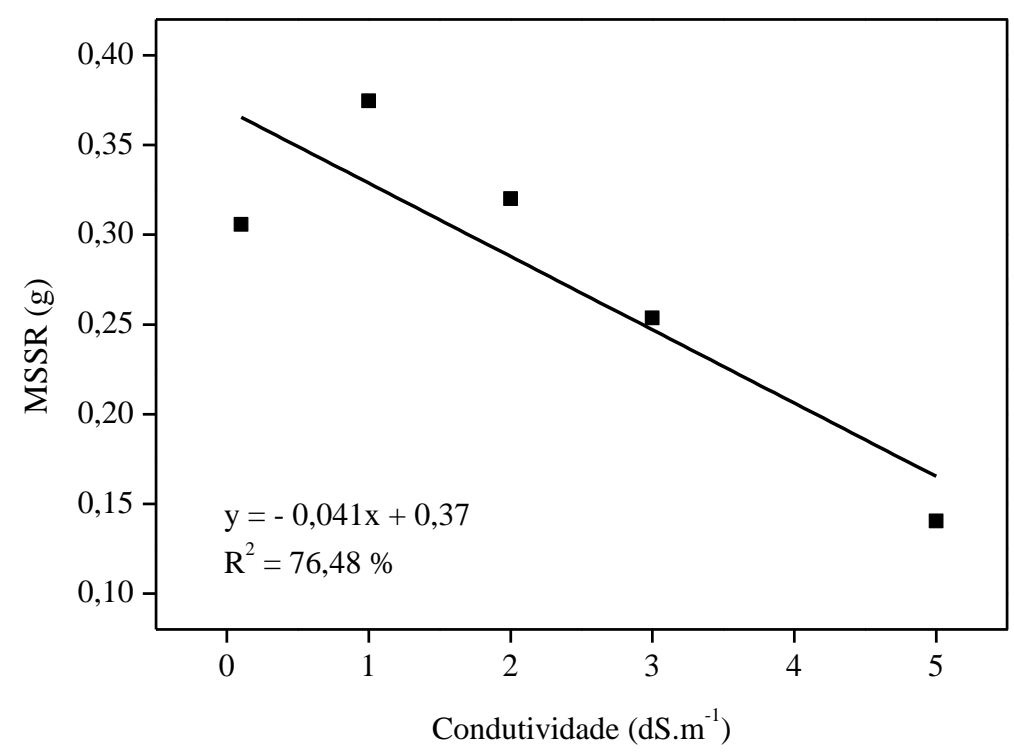

Fonte: Própria (2018)

Logo, os resultados apresentados demonstraram que a ação da salinização do substrato, dificultou o crescimento vegetativo das plântulas, com os efeitos osmóticos e tóxicos dos íons (MUNNS, 2002; L.V. et al., 2008). Portanto, a salinidade pode vir a interferir na produção de mudas de qualidade (FONSECA, 2000; BONFIM, 2007). 


\section{CONCLUSÕES}

Concentração salina superior a $1 \mathrm{dS} \cdot \mathrm{m}^{-1}$ reduz a emergência de plântulas de juçara; Concentrações salinas de até $5 \mathrm{dS} . \mathrm{m}^{-1}$ não interferem no TME e IVE de plântulas de juçara;

Plântulas de juçara têm redução do seu crescimento quando irrigadas com água com concentração salina a partir de $1 \mathrm{dS} \cdot \mathrm{m}^{-1}$.

\section{REFERÊNCIAS}

ASHRAF, M.; HARRIS, P. J. C. Potential biochemicalindicators of salinity tolerance in plants. Plant Science, v.166, p.889-899, 2004.

BARONI, D. F. Qualidade física e fisiológica de sementes de Stylosanthes capitata/macrocephala revestidas. Campos dos Goytacazes. 2018. 96 p. Dissertação (Produção Vegetal). Departamento de Fitotecnia, UENF, 2018.

BARTELS, D., SUNKAR, R. Drought and salt tolerance in plants. Critical reviews in plant sciences, v. 24, n. 1, p. 23-58, 2005.

BONFIM, A. A. Qualidade de mudas de madeira nova (Pterogyne netens Tell) produzidas em tubetes e sacolas plásticas e seu desempenho no campo. 2007. 70 p. Dissertação (Mestrado em Agronomia) - Universidade Estadual do Sudoeste da Bahia, Vitória da Conquista, 2007.

CAVALCANTE, L. F., VIEIRA, M. S., SANTOS, A. F., OLIVEIRA, W. M., NASCIMENTO, J. A. M. Água salina e esterco bovino líquido na formação de mudas de goiabeira cultivar paluma. Revista Brasileira de Fruticultura. Jaboticabal, v.32, n. 1, p. 251-261, mar. 2010.

De SOUZA, A.B.O.; BEZERRA, M.A. \& FARIAS, F.C. Germinação e desenvolvimento inicial de clones de cajueiro comum sob irrigação com água salina. Revista Brasileira de Engenharia Agrícola e Ambiental. Campina Grande - PB. v.15, n 4, p. 390-394, 2011.

FERNANDES, A. R.; CARVALHO, J. G.; CURI, N.; GUIMARÃES, P. T. G; PINTO, J. E. B. P. Crescimento de mudas de pupunheira (Bactris gasipaes H.B.K) sob diferentes níveis de salinidade. Ciência e Agrotecnologia, Lavras, v. 27, n. 2, p. 278-284, 2003.

FERREIRA NETO, M.; GHEYI, H. R.; HOLANDA, J. S. de; MEDEIROS, J. F. de; FERNANDES, P. D. Qualidade do fruto verde de coqueiro em função da irrigação com água salina. Revista Brasileira de Engenharia Agrícola e Ambiental, Campina Grande, v. 6, n.1, p. 69-75, 2002.

FIGLIORIA, M.B.; OLIVEIRA, E.C.; YAMANZOE, G.; SIQUEIRA, A.C.M.F. Conservação de sementes de Euterpe edulis Mart., em diferentes embalagens e ambientes de armazenamento. Boletim técnico do Instituto Florestal, v.41, p.355-368, 1987.

FLOWERS, T. J. Improving crop salt tolerance. Journal of Experimental Botany, Oxford, v. 55, n. 396, p. 307-319, 2004.

FONSECA, E. P. Padrão de qualidade de mudas de Trema micrantha (L.) Blume., Cedrela fissilis Vell. e Aspidosperma polyneuron Muil Arg. produzidas sob diferentes períodos de 
sombreamento. Jaboticabal, UEP, 2000. 113p. Tese (Doutorado em Agronomia) - Universidade Estadual Paulista, 2000.

HACKBART, V. C. S.; CORDAZZO, C. V. Ecologia das sementes e estabelecimento das plântulas de Hydrocotyle bonariensis Lam. Atlântica, Rio Grande, n. 25, v. 1, p. 61-65, 2003.

HOLANDA, S. J. R.; ARAUJO, F. S.; GALLÃO, M. I.; MEDEIROS FILHO, S. Impacto da salinidade no desenvolvimento e crescimento de mudas de carnaúba (Copernicia prunifera (Miller) H. E. Moore). Revista Brasileira de Engenharia Agrícola e Ambiental, Campina Grande, v. 15, n. 1, p. 47-52, 2011.

KLAFKE, A. V., LOPES, R. R., FRANKE, L. B. Desempenho de sementes nuas e revestidas de azevém-anual em condições de estresse salino. Brazilian journal of animal science, 41(5), 1093-1099. 2012.

LIMA, M. G. S.; LOPES, N. F.; MORAES, D. M.; ABREU, C. M. Qualidade fisiológica de sementes de arroz submetidas a estresse salino. Revista Brasileira de Sementes, Londrina, v. 27, n. 1, p. 54-61, 2005.

LV, S.; ZHANG, K.; GAO, Q.; LIAN, L.; YINGJIE, L.; YINGJIE, C.; ZHANG, J. Overexpression of an $\mathrm{H}+$-PPase gene from Thellungiella halophila in cotton enhances salt tolerance and improves growth and photosynthetic performance. Plant \& Cell Physiology, v. 49, n. 08 , p. 1150-1164, 2008.

MARINHO, F. J. L.; GHEYI, H. R.; FERNANDES, P. D. Germinação e formação de mudas de coqueiro irrigadas com águas. Revista Brasileira de Engenharia Agrícola e Ambiental, Campina Grande, v. 9, n. 3, p. 334-340, 2005.

MARTINS, C.C.; NAKAGAWA, J.; BOVI, M.L.A. Efeito da posição da semente no substrato e no crescimento inicial das plântulas de Palmito-Vermelho (Euterpe espiritosantensis Fernandes Palmae). Revista Brasileira de Sementes, Brasília, v. 21, n. 1, p. 164-173, 1999.

MUNNS, R. Comparative physiology of salt and water stress. Plant Cell \& Environment, v.25, p.239-250, 2002.

NASCIMENTO, D. F.; LELES, P. S. S.; OLIVEIRA NETO, S. N.; MOREIRA, R. T. S.; ALONSO, J. M. Crescimento inicial de seis espécies florestais em diferentes espaçamentos. Cerne, v.18, p.159 165, 2012.

REIS, A. Dispersão de sementes de Euterpe edulis Martius (Palmae) em uma floresta ombrófila densa Montana da Encosta Atlântica em Blumenau, SC. Tese de Doutorado - Universidade Estadual de Campinas, 162p. 1995.

REITZ, R.; KLEIN, R.M.; REIS, A. Projeto madeira de Santa Catarina. Itajaí: SUDESUL IBDE, 1978. 315p.

ROYER, M.R.; DAQUILA, B.V.; DEMIZU, F.S.B.; ZANATTA, S.C. Tratamentos para superação da dormência em sementes de palmito juçara. Congresso Nacional de Pesquisa e Ensino em Ciências. Campina Grande, Paraíba. 2016.

SILVA, E. N. et al. Acúmulo de íons e crescimento de pinhão manso sob diferentes níveis de salinidade. Revista Ciência Agronômica, v. 40, n. 02, p. 240-246, 2009. 
TAIZ, L., ZEIGER, E. Fisiologia vegetal. 4. ed. Porto Alegre: Artmed, 848p. 2009.

TESTER, M.; DAVENPORT, R. Na+ tolerance and Na+ transport in higher plants. Annals of Botany, Oxford, v. 91, n. 3, p. 503-527, 2003. 